Article

\title{
HPLC-PDA-MS/MS Characterization of Bioactive Secondary Metabolites from Turraea fischeri Bark Extract and Its Antioxidant and Hepatoprotective Activities In Vivo
}

\author{
Mansour Sobeh ${ }^{1, *}$, Mona F. Mahmoud ${ }^{2}$, Omar M. Sabry ${ }^{3}$, Rasha Adel ${ }^{4}$, Malak Dmirieh ${ }^{1}$, \\ Assem M. El-Shazly ${ }^{4}$ and Michael Wink ${ }^{1, *}$ \\ 1 Institute of Pharmacy and Molecular Biotechnology, Heidelberg University, Im Neuenheimer Feld 364, \\ Heidelberg 69120, Germany; Dmirieh@stud.uni-heidelberg.de \\ 2 Department of Pharmacology and Toxicology, Faculty of Pharmacy, Zagazig University, \\ Zagazig 44519, Egypt; mona_pharmacology@yahoo.com \\ 3 Department of Pharmacognosy, College of Pharmacy, Cairo University, Cairo 11562, Egypt; \\ omar.sabry@pharma.cu.edu.eg \\ 4 Department of Pharmacognosy, Faculty of Pharmacy, Zagazig University, Zagazig 44519, Egypt; \\ rashaadelelfeqy@gmail.com (R.A.); assemels2002@yahoo.co.uk (A.M.E.-S.) \\ * Correspondence: sobeh@uni-heidelberg.de (M.S.); wink@uni-heidelberg.de (M.W.); \\ Tel.: +49-6221-54-4880 (M.W.); Fax: +49-6221-54-4884 (M.W.)
}

Received: 6 November 2017; Accepted: 27 November 2017; Published: 29 November 2017

\begin{abstract}
Turraea fischeri is an East African traditional herb, which is widely used in traditional medicine. In this study, we profiled the secondary metabolites in the methanol extract of $T$. fischeri bark using HPLC-PDA-ESI-MS/MS, and 20 compounds were tentatively identified. Several isomers of the flavonolignan cinchonain-I and bis-dihydroxyphenylpropanoid-substituted catechin hexosides dominated the extract. Robust in vitro and in vivo antioxidant properties were observed in 1,1-diphenyl2-picrylhydrazyl radical scavenging assay (DPPH) and ferric reducing antioxidant power (FRAP) assay, and in the model organism Caenorhabditis elegans. Additionally, the extract exhibited promising hepatoprotective activities in D-galactosamine (D-GaIN) treated rats. A significant reduction in the elevated levels of aspartate aminotransferase (AST), total bilirubin, gamma-glutamyltransferase (GGT), and malondialdehyde (MDA) and increase of glutathione (GSH) was observed in rats treated with the bark extract in addition to D-galactosamine when compared with rats treated with D-galactosamine alone. In conclusion, T. fischeri is apromising candidate for health-promoting and for pharmaceutical applications.
\end{abstract}

Keywords: Turraea fischeri; flavonolignan; cinchonains; HPLC-PDA-ESI-MS/MS; antioxidant; hepatoprotection

\section{Introduction}

Although oxygen metabolism is a central key to life, it is also associated with reactive oxygen species (ROS) production; this phenomenon is known as the "Oxygen Paradox". A large number of diseases, including cardiovascular diseases, stroke, cancer, diabetes, Parkinson, and Alzheimer disease, are apparently linked to ROS. Also, ageing and several age-related degenerative diseases involve inflammation and deleterious tissue damage from oxidative components. This also applies to liver cirrhosis [1].

In the body, some endogenous antioxidant enzymes are able to cope with ROS, and thus can limit the damage of ROS. However, in many diseases, among them liver injury, the antioxidant abilities 
are diminished or severely compromised. In the case of excessive amounts of ROS, other protective mechanisms, such as external antioxidants, could be of a great value [2,3].

The genus Turraea L. of the Meliaceae family comprises more than 70 species in Africa, Madagascar, Socotra, and tropical Asia; Turraea plants grow as trees or shrubs [4]. The genus is rich in secondary metabolites, such as limonoids, sterols, and flavonoids [5]. Several species from the genus were systematically investigated for their potential as antimalarial agents, among them, T. vogelii, T. robusta, T. nilotica, T. floribunda, and T. fischeri [6-8]. Also, some African Turraea species are traditionally used as an aphrodisiac and for the treatment of wounds, abscesses, asthma, and against bilharzias [9].

Turraea fischeri Gürke is an East African traditional herb and is widely used in folk medicine against stomachache and for fertility properties [10]. However, neither phytochemical studies nor biological investigations have been carried out for this plant. Therefore, this work describes for the first time the chemical constituents of a methanol extract of Turraea fischeri bark using HPLC-PDA-ESI-MS/MS. The in vivo hepatoprotection against D-galactosamine (D-GaIN) in toxication in rats and antioxidant properties in the nematode Caenorhabditis elegans, which is a widely used model system in this context [11,12], were evaluated.

\section{Results and Discussion}

\subsection{Phytochemicals in T. fischeri Bark}

HPLC-PDA-MS/MS was applied to profile the secondary metabolites of a methanol extract from T. fischeri bark, and 20 compounds were tentatively identified (Figures 1 and 2, and Table 1). Flavonolignans and bis-dihydroxyphenylpropanoid-substituted catechin isomers dominated the extract.

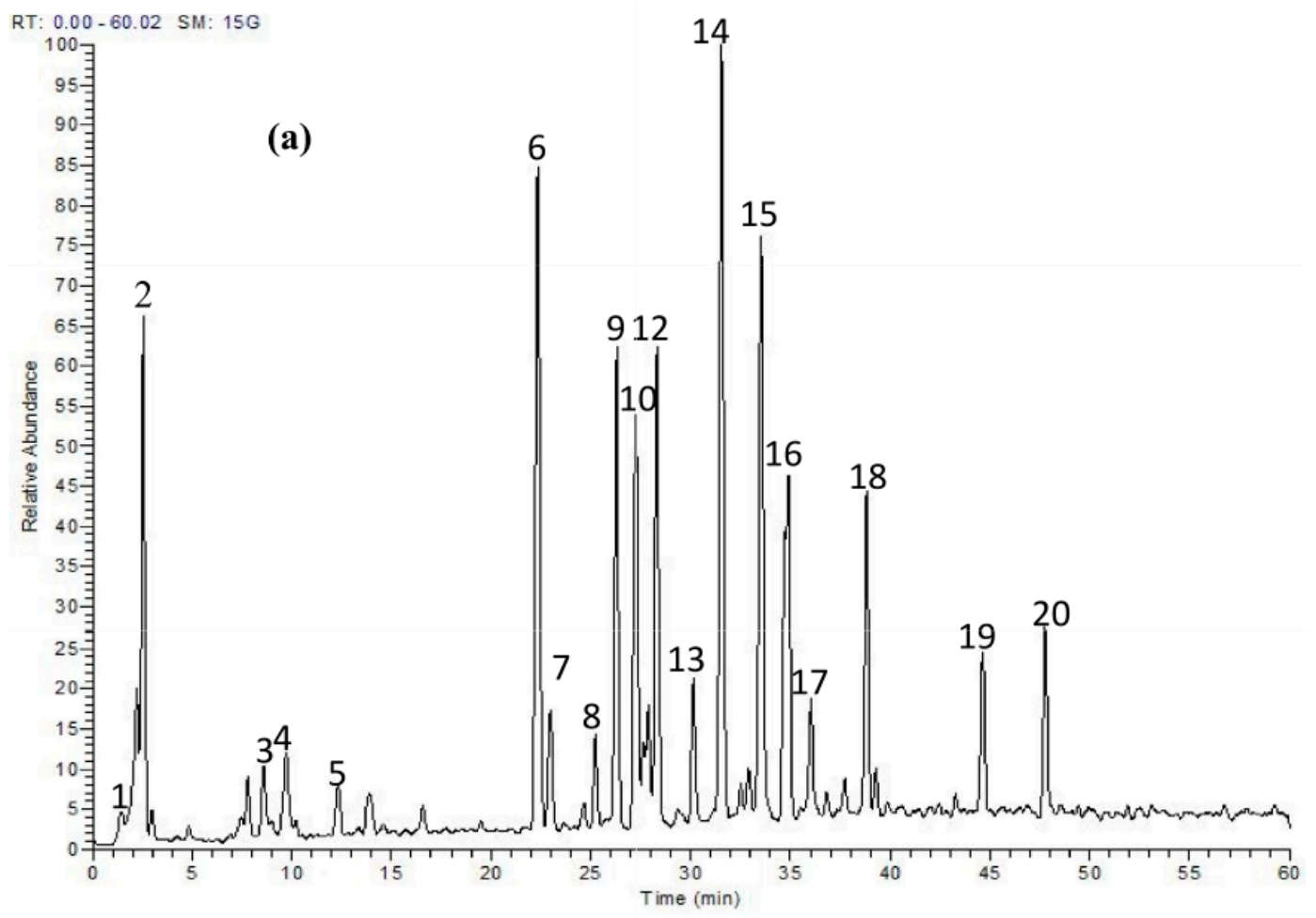

Figure 1. Cont. 


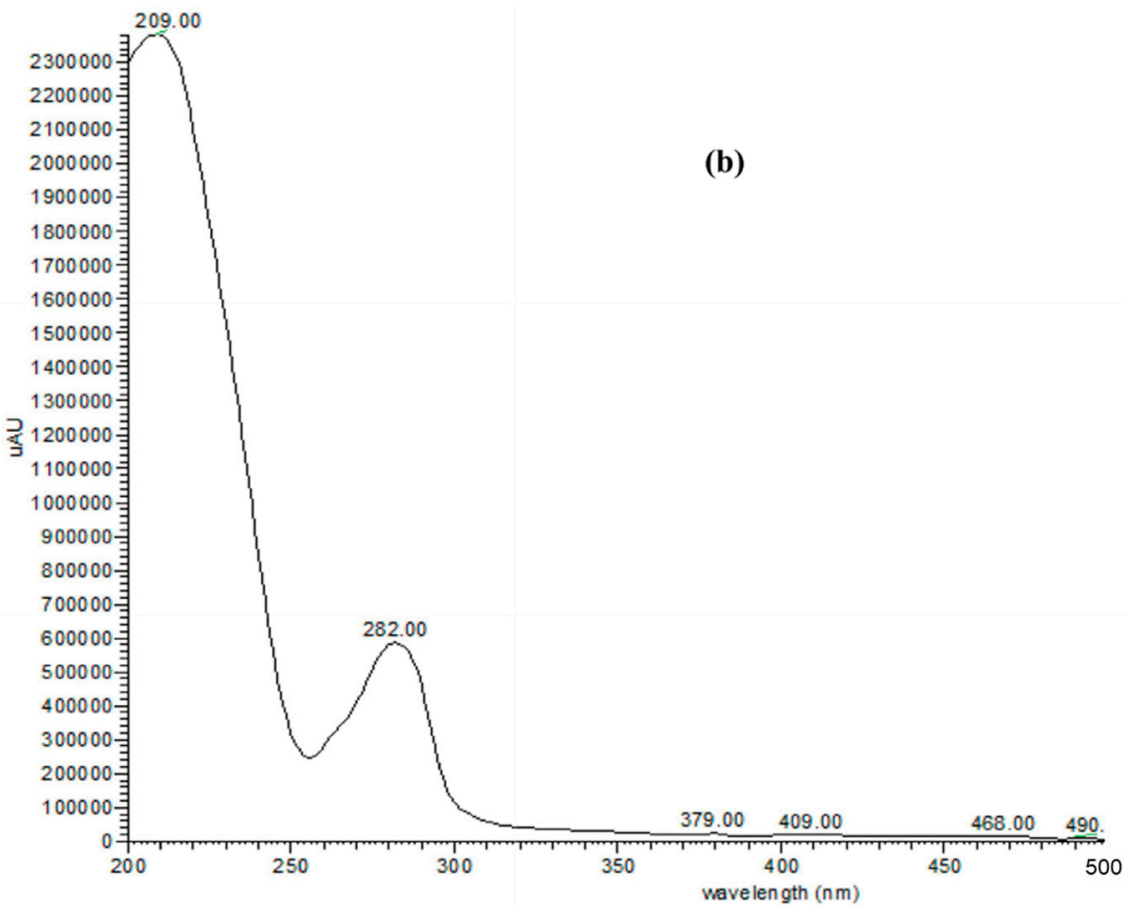

Figure 1. (a) HPLC-ESI (-)-MS/MS profile of a methanol extract of T. fischeri bark; (b) A sample spectra (UV) of compounds (3-20) at $280 \mathrm{~nm}$.

Table 1. Tentative identification of secondary metabolites of a methanol extract of $T$. fischeri bark using HPLC-PDA-MS/MS in the negative ion mode.

\begin{tabular}{|c|c|c|c|c|}
\hline No. & $t_{\mathrm{R}}$ & {$[\mathbf{M}-\mathbf{H}]^{-}$} & MS/MS Fragments & Tentatively Identified Compounds \\
\hline 2 & 2.00 & 353 & 179,191 & Chlorogenic acid \\
\hline 1 & 1.65 & 447 & 315,153 & Protocatechuic acid pentosyl-hexoside \\
\hline 15 & 33.41 & 451 & 299,341 & Cinchonain-I * \\
\hline 9 & 26.27 & 613 & $299,341,451,595$ & Cinchonain-I hexoside * \\
\hline 10 & 27.69 & 613 & $299,341,451,595$ & Cinchonain-I hexoside * \\
\hline 6 & 22.39 & 759 & $299,323,433,451,613,649$ & Cinchonain-I rhamnosyl-hexoside * \\
\hline 12 & 28.27 & 759 & $299,323,433,451,613,649$ & Cinchonain-I rhamnosyl-hexoside * \\
\hline 13 & 30.11 & 759 & $299,323,433,451,613,649$ & Cinchonain-I rhamnosyl-hexoside * \\
\hline 17 & 36.1 & 759 & $299,323,433,451,613,649$ & Cinchonain-I rhamnosyl-hexoside * \\
\hline 16 & 34.76 & 775 & $305,393,461,503,613,665$ & Bis-dihydroxyphenylpropanoid-substituted catechin hexoside ${ }^{* *}$ \\
\hline 20 & 47.74 & 775 & $305,393,461,503,613,665$ & Bis-dihydroxyphenylpropanoid-substituted catechin hexoside ** \\
\hline 5 & 12.24 & 793 & $341,299,451,503,613,639$ & Cinchonain-I syringyl-hexoside * \\
\hline 19 & 44.64 & 921 & $305,461,485,595,613,811$ & $\begin{array}{l}\text { Bis-dihydroxyphenylpropanoid-substituted catechin } \\
\text { rhamnosyl-hexoside }\end{array}$ \\
\hline 3 & 8.54 & 939 & $289,613,759$ & $\begin{array}{l}\text { Bis-dihydroxyphenylpropanoid-substituted catechin } \\
\text { syringyl-rhamnoside }\end{array}$ \\
\hline 4 & 9.72 & 939 & $289,433,613,759$ & $\begin{array}{l}\text { Bis-dihydroxyphenylpropanoid-substituted catechin } \\
\text { syringyl-rhamnoside }\end{array}$ \\
\hline
\end{tabular}

* indicates that the stereochemistry of the compounds is not resolved; this compound could be cinchonain-Ia, Ib, Ic, or Id. ** indicates that the stereochemistry of the compounds is not resolved. The compounds are arranged based on their molecular weights. Compounds are numbered in accordance to Figure 1. 
<smiles>O=C1CC(c2ccc(O)c(O)c2)c2c(cc(O)c3c2OC(c2ccc(O)c(O)c2)C(O)C3)O1</smiles>

Cinchonain I<smiles>O=C1CC2=C(C(c3ccc(O)c(O)c3)C1)C1(CC(=O)OC(c3ccc(O)c(O)c3)C1)OC(c1ccc(O)c(O)c1)C2c1ccc(O)c(O)c1</smiles>

Bis-dihydroxyphenylpropanoid-substitued catechin

$\mathrm{R}=$ hexose, and/ or rhamnose

Figure 2. Tentative structures of some compounds from Table 1.

For instance, peak (15) at a retention time $33.41 \mathrm{~min}$, exhibited a molecular ion peak $[\mathrm{M}-\mathrm{H}]^{-}$ $(m / z)$ at 451 and two daughter ions at $m / z 341$ and 299; it was assigned to cinchonain-I, as previously described [13] (Figure 3a). Three peaks (8, 9, and 10) at retention times 25.24, 26.27, and 27.69, respectively, showed $[\mathrm{M}-\mathrm{H}]^{-}(\mathrm{m} / \mathrm{z})$ at 613 and three fragment ions at 299, 341, and 451; they were identified as cinchonain-I-hexoside isomers (Figure 3b).

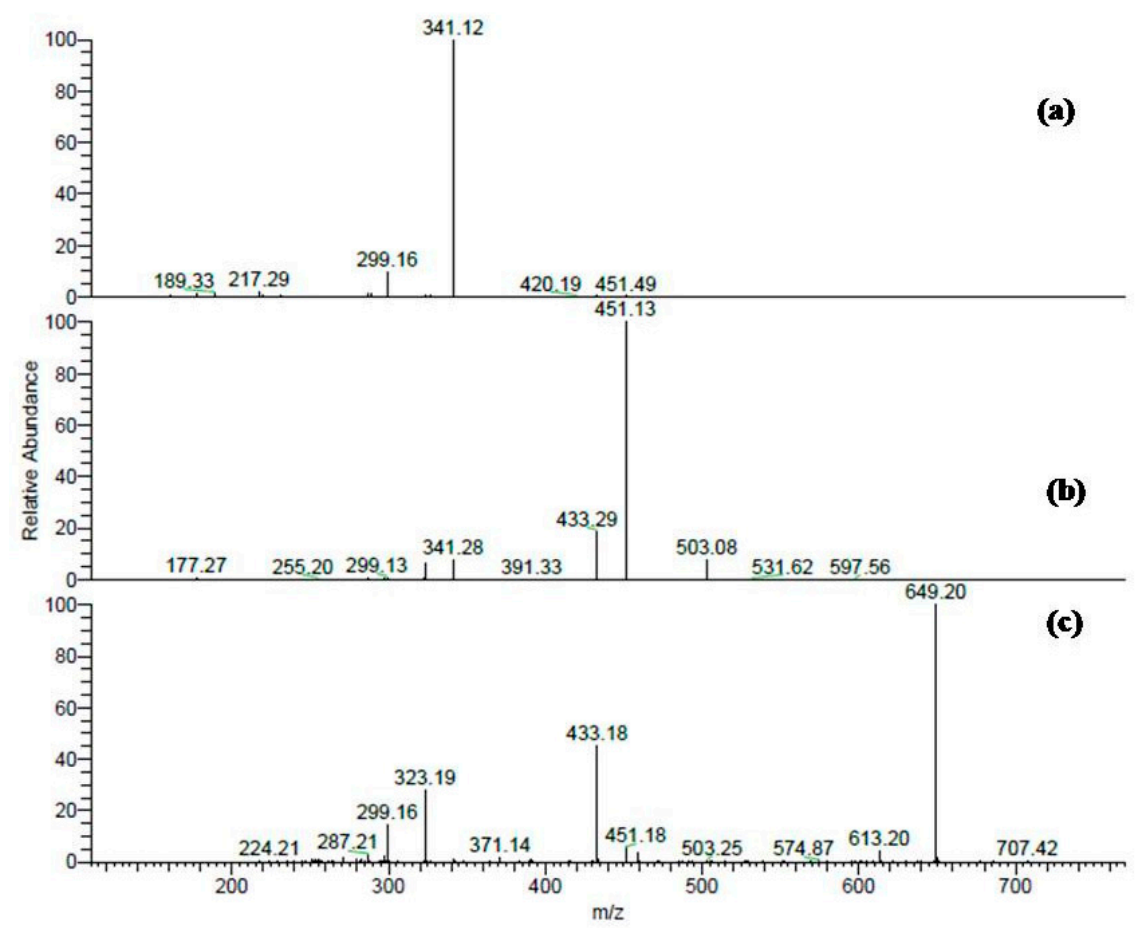

Figure 3. (a) MS/MS fragmentation of cinchonain-I at $[\mathrm{M}-\mathrm{H}]^{-}(\mathrm{m} / \mathrm{z})$ at 451 ; (b) MS/MS fragments of cinchonain-I hexoside at $[\mathrm{M}-\mathrm{H}]^{-}(\mathrm{m} / z)$ at 613; (c) MS/MS spectra of cinchonain-I rhamnosyl-hexoside at $[\mathrm{M}-\mathrm{H}]^{-} m / z 759$.

Also, six further compounds $(6,7,11,12,13$, and 17) displayed similar molecular ion peaks at $[\mathrm{M}-\mathrm{H}]^{-}(m / z) 759$. In MS/MS analyses, they produced fragment ions as $649(\mathrm{M}-\mathrm{H}-110)$, 613 (M-H-146, rhamnose moiety), and 451 (M-H-146-162, rhamnose and hexose moieties); they were characterized as cinchonain-I rhamnosyl-hexoside isomers (Table 1, Figure 3c). Additionally, a minor compound (5) at a retention time $12.24 \mathrm{~min}$ had $[\mathrm{M}-\mathrm{H}]^{-} \mathrm{m} / z 793$ and in $\mathrm{MS}^{2}$ demonstrated daughter ions at $m / z 613$ (M-H-180, syringyl moiety) and 451 (M-H-180-162, syringyl and hexoside moieties); it was tentatively identified as cinchonain-I syringyl-hexoside (Table 1 and Figure 4). 


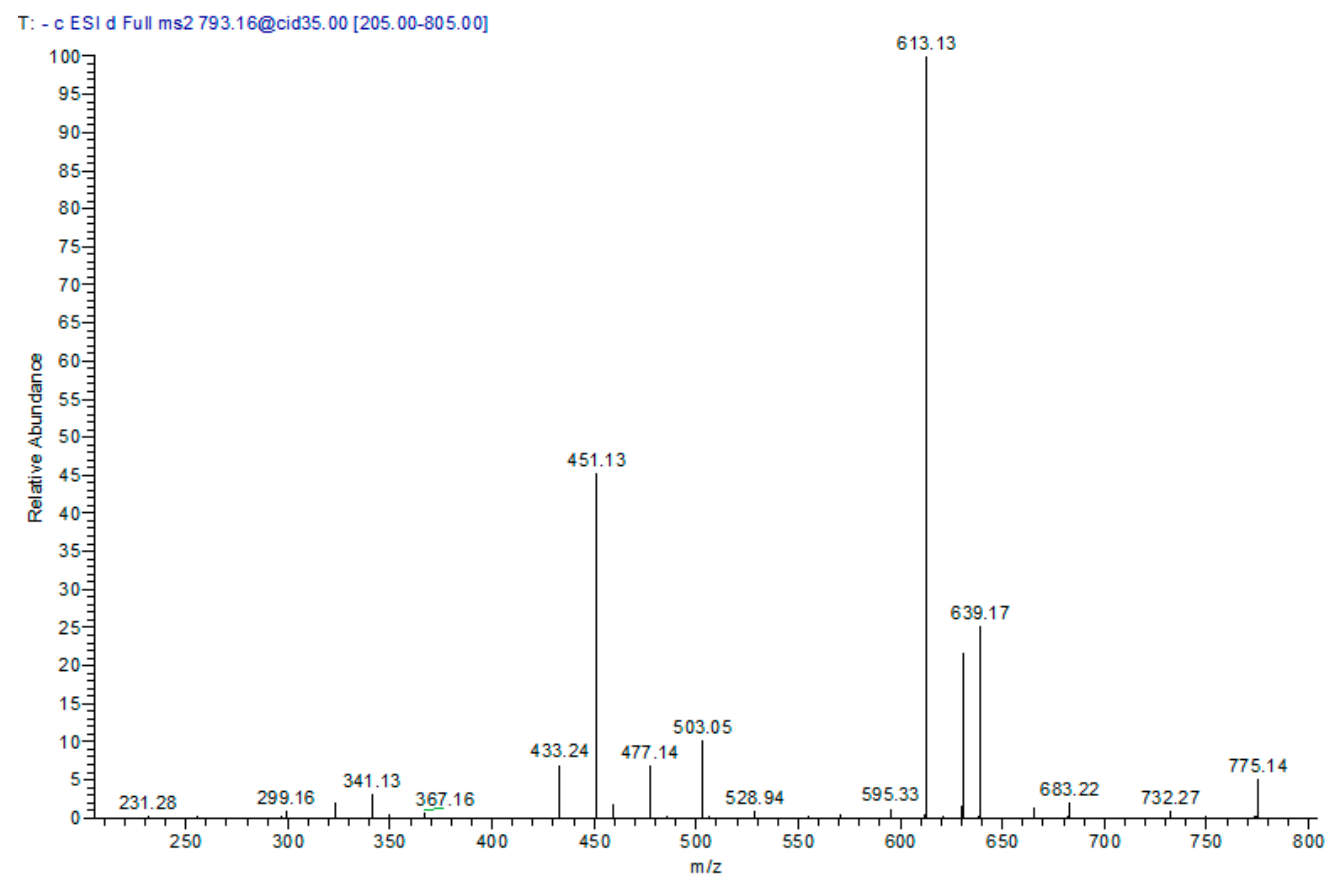

Figure 4. MS/MS spectra of cinchonain-I syringyl-hexoside at $[\mathrm{M}-\mathrm{H}]^{-} m / z 793$.

Two peaks at 34.76 and 47.74 min (compounds 16 and 20) with a molecular ion of [M $-\mathrm{H}]^{-}$at $m / z 775$ were detected. In MS ${ }^{2}$, they produced a major ion peak at $m / z 613$ [M-H-162, loss of a hexose moiety]. In $\mathrm{MS}^{3}$ of 613 , two daughter ions at $m / z 503$ and 461 were observed; thus, they were identified as bis-dihydroxyphenylpropanoid-substituted catechin hexoside isomers, as reported before [13] (Figures 5a,b and 6).

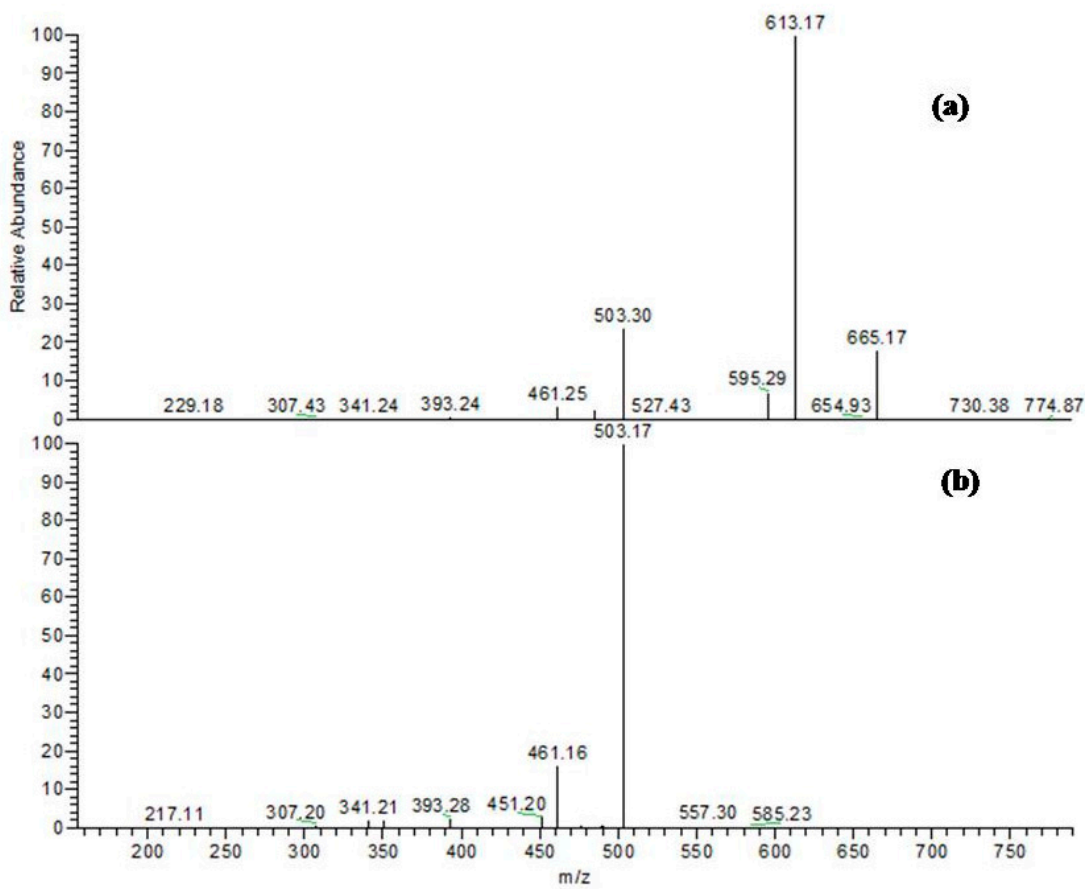

Figure 5. Negative ion ESI-MS/MS spectra of bis-dihydroxyphenylpropanoid-substituted catechin-hexoside; (a) $\mathrm{MS}^{2}$ of $[\mathrm{M}-\mathrm{H}]^{-} \mathrm{m} / z \mathrm{z75}$; (b) $\mathrm{MS}^{3}$ of main daughter ion at $m / z 613$. 


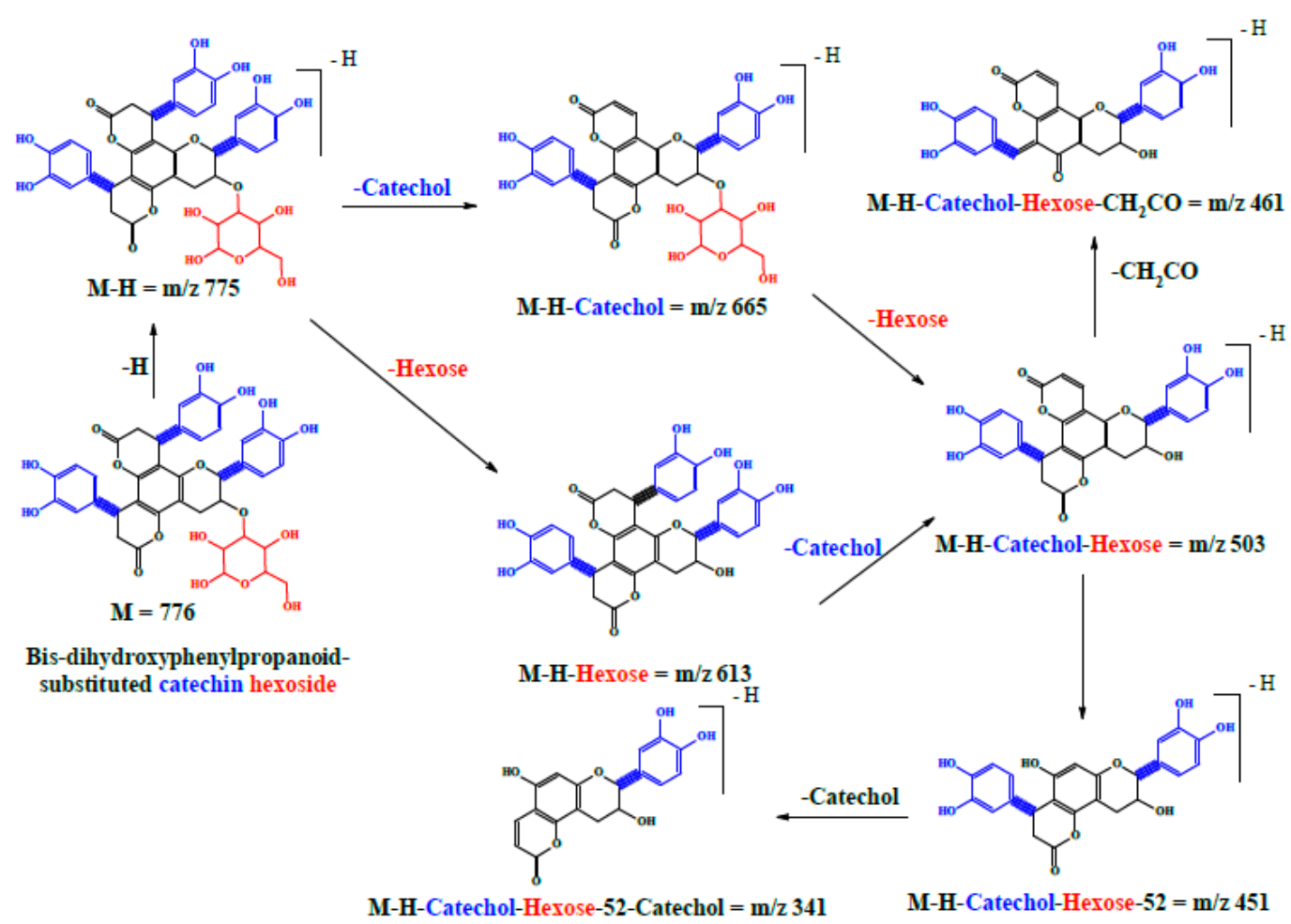

Figure 6. A proposed fragmentation pattern of bis-dihydroxyphenylpropanoid-substituted catechin hexoside at $[\mathrm{M}-\mathrm{H}]^{-} m / z 775$.

In the extract, three compounds $\left(\mathbf{1 4}, \mathbf{1 8}\right.$, and 19) had similar $[\mathrm{M}-\mathrm{H}]^{-}$at $m / z 921$, as well as similar fragmentation pattern. In $\mathrm{MS}^{2}$, they produced a major daughter ion at $m / z 811$ due to the loss of dihydroxyphenyl group. Also, the two ions at $m / z 775$ and 613 were produced due to the losses of 146 and 162, respectively. Therefore, these three precursors were tentatively assigned to bis-dihydroxyphenylpropanoid-substituted catechin rhamnosyl-hexoside isomers. Their retention times are documented in Table 1 and a representative mass spectrum is presented in Figure 7. Other two minor peaks (3 and 4) produced a molecular ion peak at $[\mathrm{M}-\mathrm{H}]^{-} m / z 939$ and fragment ions at 759 and 613; they were tentatively characterized as bis-dihydroxyphenylpropanoid-substituted catechin syringyl-rhamnoside isomers (Table 1).

\subsection{Antioxidant and Hepatoprotective Activities}

In initial analyses, we determined the total phenolic content of a bark extract using the Folin-Ciocalteu method. The extract contained $488 \mathrm{mg}$ gallic acid equivalent/g extract. Next, we assessed the in vitro antioxidant properties of this extract by DPPH (1,1-diphenyl-2-picrylhydrazyl radical scavenging assay) and FRAP (Ferric reducing antioxidant power) assay. A pronounced antioxidant activity was detected in both of the assays in comparison to the potent antioxidant compound ascorbic acid (Table 2). Comparable antioxidant properties were reported in Trichilia catigua and Parabarium huaitingii $[14,15]$.

Table 2. Antioxidant properties of a methanol extract from T. fischeri bark.

\begin{tabular}{ccc}
\hline Sample & Bark Extract & AscorbicAcid \\
\hline $\mathrm{DPPH}\left(\mathrm{EC}_{50}, \mu \mathrm{g} / \mathrm{mL}\right)$ & 5.12 & 3.31 \\
FRAP $\left(\mathrm{mM} \mathrm{FeSO}_{4} / \mathrm{mg}\right.$ extract $)$ & 18.32 & 22 \\
\hline
\end{tabular}




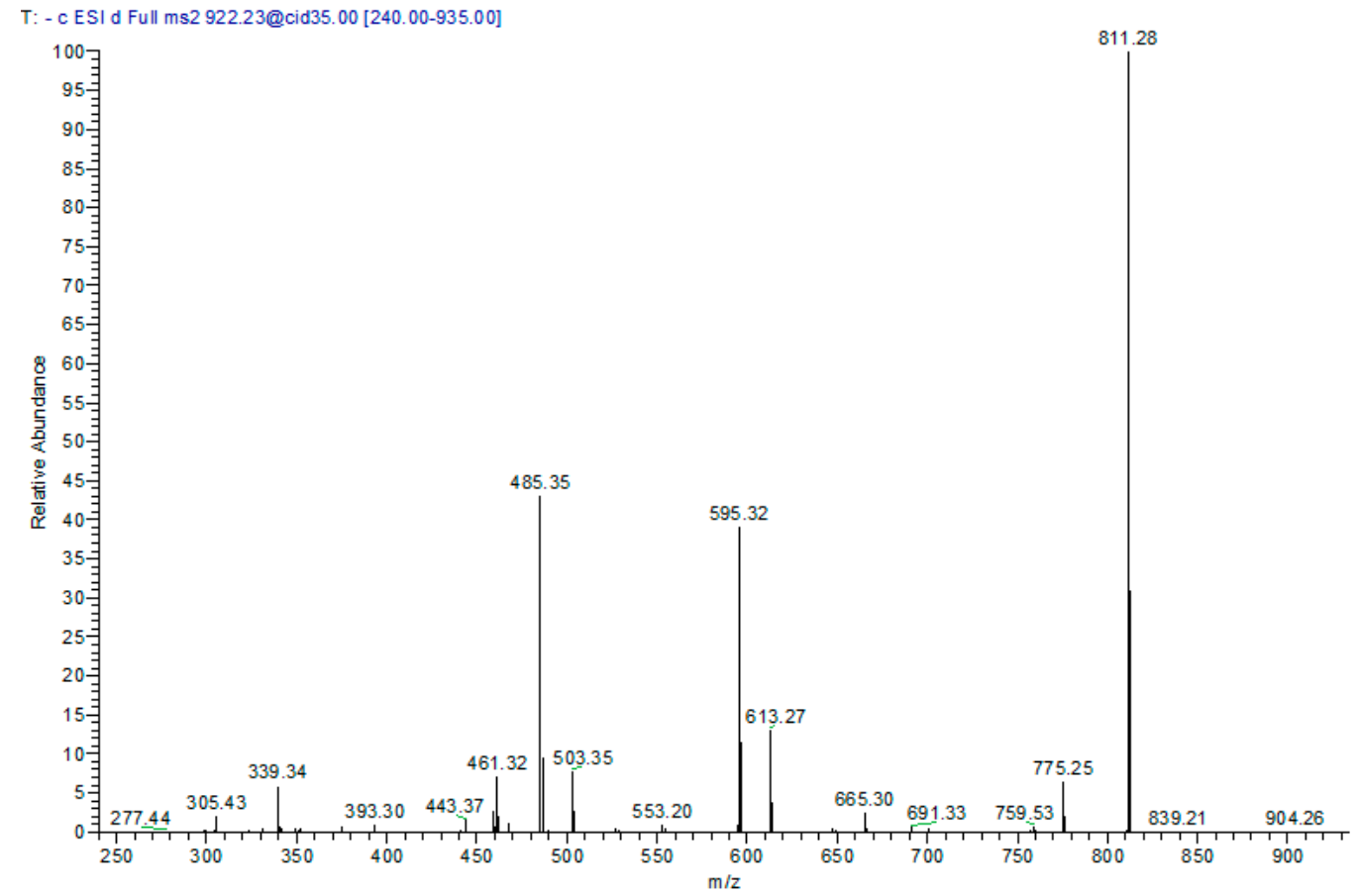

Figure 7. Negative ion ESI-MS/MS spectra of bis-dihydroxyphenylpropanoid-substituted catechin rhamnosyl-hexoside at $[\mathrm{M}-\mathrm{H}]^{-} m / z 921$.

In the next step, we investigated whether these in vitro antioxidant activities would induce protective effects in vivo in C. elegans. We initially studied the survival rate of the wild type N2 worms that were treated with the toxic and pro-oxidant juglone $(80 \mu \mathrm{M})$ to generate oxidative stress that is lethal within $24 \mathrm{~h}$. The pre-treatment of the worms with the extract resulted in an increased survival rate in a dose dependent manner (Figure 8a).

Given these initial findings, we went further to assess the abilities of the extract to diminish ROS production or at least scavenge it. Thus, the intracellular ROS level was quantified in N2 worms against elevated ROS levels. The extract reduced the ROS level in a concentration dependent pattern (Figure 8b).

Prolonged exposure to extreme stress conditions can harm cells, damage proteins, and thus result in cell and tissue death. Heat-shock proteins (HSPs) can be detected in all of the studied organisms, and they are increasingly expressed in the stressed cells to protect and/or repair such damage by preventing protein aggregation and misfolding, and to maintain homeostasis [16]. To explain the possible mechanism of the observed in vivo antioxidant activities of the extract, we incubated the transgenic strains TJ375 with $20 \mu \mathrm{M}$ juglone for $24 \mathrm{~h}$ to induce oxidative stress, and then we measured the expression of the green fluorescent protein (GFP) in Phsp-16.2::GFP in the pharynx. The extract significantly reduced HSP-16.2 expression in a dose-dependent fashion (Figure 8c).

To further elucidate the mechanisms by which the extract exerts its antioxidant activities, we assessed its effects on the localization of the FOXO transcription factor DAF-16. The translocation of DAF-16 from the cytosol into the nucleus is a primary prerequisite for its ability to promote the expression of several defense enzymes, among them, superoxide dismutase and heat-shock proteins [17]. Apparently, the extract increased nuclear localization of DAF-16::GFP in daf-16-jfp reporter strain (transgenic strain TJ356), indicating a reduced DAF-16 phosphorylation status after extract treatment in a dose-dependent pattern (Figure $8 \mathrm{~d}$ ). This suggests that the in vivo antioxidant activities of $T$. fischeri extract might be mediated by the DAF-16/FOXO pathway. In conclusion, the polyphenolics in the bark extract are bioavailable and are partly taken up by $C$. elegans. The results agree with those of earlier experiments in our laboratory [18-21]. 
In light of these in vitro and in vivo findings, we investigated the hepatoprotective potential of the bark extract against the severe effects of liver intoxication in the well established rat model after injection of D-galactosamine (D-GaIN) [22]. We first investigated the biochemical changes in the liver enzymes after $24 \mathrm{~h}$ of D-GalN injection. A significant elevation in liver enzyme activities (aspartate aminotransferase (AST), alanine aminotransferase (ALT)) and total bilirubin were observed in D-GalN-rats. Pretreatment of the rats with $200 \mathrm{mg} / \mathrm{kg}$ extract and silymarin attenuated the increase in ALT and AST activities, and total bilirubin $(p<0.05$, Figure 8). However, pretreatment with $100 \mathrm{mg} / \mathrm{kg}$ b.w. extract significantly decreased AST and gamma-glutamyltransferase (GGT) levels when compared with D-GalN $(p<0.05)$, but did not affect ALT and total bilirubin when compared with D-GalN $(p>0.05$, Figure 9).
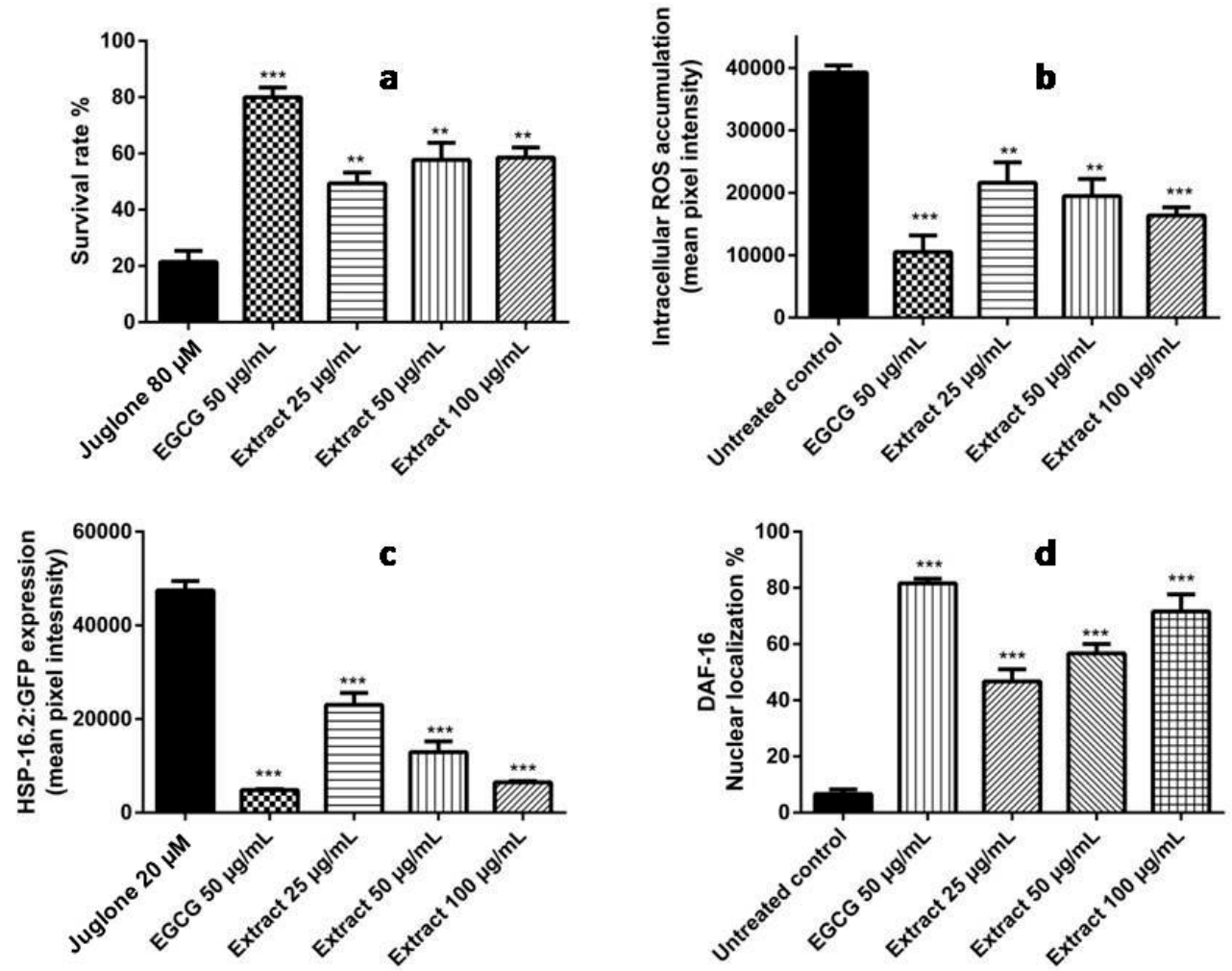

Figure 8. (a) Influence of T. fischeri extract on the survival rate in $\mathrm{N} 2$ worms against the deleterious effects of juglone $(80 \mu \mathrm{M})$. The extract improved the survival rate to $49.39 \%, 57.73 \%$ and $58.54 \%$ at concentrations of 25,50 , and $100 \mu \mathrm{g} / \mathrm{mL}$, respectively, when compared to the juglone-alone control (21.49\%), (mean \pm SEM, $n=3$ ); (b) Influence on intracellular ROS accumulation in N2 nematodes evidenced by H2DCF-DA dye. A significant reduction was observed in ROS levels by $44.96 \%, 50.44 \%$ and $58.32 \%$ when the worms were treated with 25,50 , and $100 \mu \mathrm{g} / \mathrm{mL}$ extract, respectively; the control was set $100 \%$. ROS levels were measured by fluorescence microscopy. Data are expressed as relative fluorescent intensity compared to control group (mean \pm SEM, $n=3$ ); (c) Influence of the extract on Phsp-16.2::GFP expression in mutant strains TJ375. Phsp-16.2::GFP levels were significantly decreased by $51.49 \%, 72.73 \%, 86.36 \%$ after pre-treatment of the nematodes with 25,50 , and $100 \mu \mathrm{g} / \mathrm{mL}$ extract followed by $20 \mu \mathrm{M}$ juglone; (d) Influence of the extract on the localisation of the transcription factor DAF-16 in mutant TJ356 strains. The extract induced nuclear localization to $46.67 \%, 56.67 \%$, and $71.67 \%$ at concentrations of 25,50 , and $100 \mu \mathrm{g} / \mathrm{mL}$ extract, respectively. DAF-16::GFP localization was determined using fluorescence microscopy. The worms were assigned into three groups: cytosolic, intermediate, and nuclear according to their phenotype. ${ }^{* *} p<0.01,{ }^{* * *} p<0.001$ related to control was analysed by one-way ANOVA. Interestingly, the extract showed comparable activities with the reference compound epigallocatechin gallate (EGCG) in all assays. 

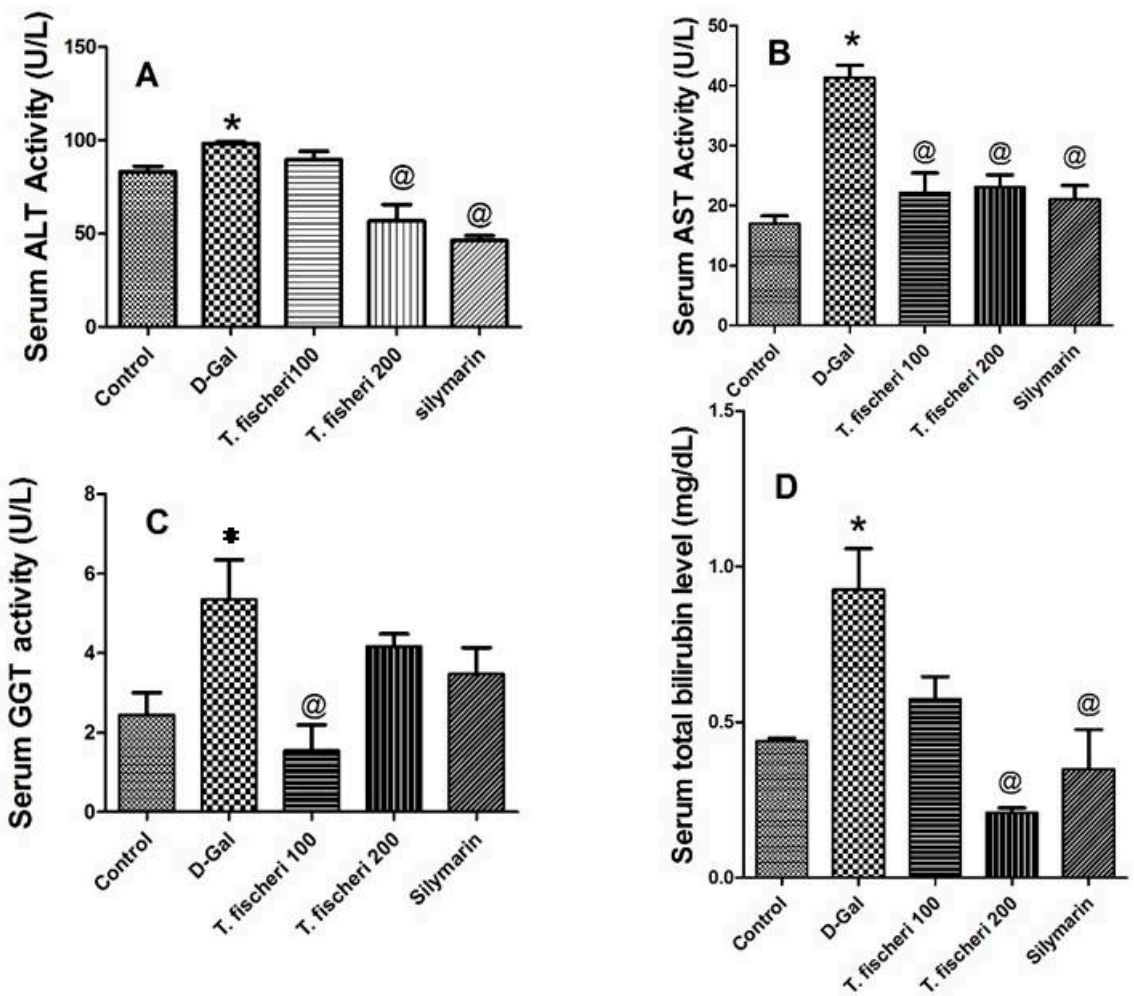

Figure 9. Influence of a single oral dose of D-galactosamine-induced liver injury $(800 \mathrm{mg} / \mathrm{kg})$ and oral administration of two doses $(100 \mathrm{mg} / \mathrm{kg}$ and $200 \mathrm{mg} / \mathrm{kg}$ b.w.) of $\mathrm{T}$. fischeri extract and the positive control silymarin $(100 \mathrm{mg} / \mathrm{kg})$ on serum enzyme activities (A) alanine aminotransferase (ALT); (B) aspartate aminotransferase (AST); (C) gamma-glutamyltransferase (GGT); (D) Total bilirubin level. Results are expressed as mean \pm SEM. * Significant difference compared to normal control group; @ Significant difference compared to D-GalN treated group at $p<0.05 . n=6$; by One Way ANOVA and Tukey post hoc test.

Furthermore, we studied the influence of T. fischeri extract on oxidative stress markers. D-GalN injection increased the generation of ROS and reduced the level of endogenous antioxidants. This resulted in an increased oxidative stress, as revealed by elevation of malondialdehyde (MDA), a marker of lipid peroxidation and depletion of glutathione (GSH) $(p<0.05$, Figure 10). Oral administration of T. fischeri extract in doses of $100 \mathrm{mg} / \mathrm{kg}$ and $200 \mathrm{mg} / \mathrm{kg}$ b.w. and silymarin revealed potent antioxidant effect. It diminished the elevated MDA content and increased endogenous GSH when compared to D-GalN alone ( $p<0.05$, Figure 10). The effect of the extract in either dose levels was similar to silymarin on MDA but the latter exerted a stronger effect on GSH.

Apparently, the studied extract exerted pronounced hepatoprotective activities, as evidenced by the biochemical activities of the liver enzymes and the ROS markers GSH and MDA. Additional evidence was found when the histopathological changes were investigated. D-GalN caused focal hepatic necrosis and hepatic inflammation as revealed by mononuclear cell infiltration (Figure 11B). Furthermore, acute cell swelling and intense microsteatosis were also observed in the hepatic cells. Single or multiple hepatic cells showed apoptosis. Moreover, vasculitis and endotheliosis affected some portal areas. The majority of portal areas showed intense portal fibrosis and inflammation, as revealed by mononuclear cells infiltration and contain proliferative bile ductules. In $T$. fischeri (100 mg extract $/ \mathrm{kg}$ ) treated group, moderate microscopic changes represented by diffuse acute cells welling and mild portal fibrosis were encountered (Figure 11C). The portal vasculatures were dilated and showed lymphocytosis and scattered minute microsteatosis in individualized hepatic cells. The remaining hepatic parenchyma was apparently normal. Pretreatment with $200 \mathrm{mg} / \mathrm{kg}$ of the extract exerted a better improvement in the structural changes of the liver where only portal 
inflammation was observed (Figure 11D). The effect of the known liver protectant silymarin was similar to the $200 \mathrm{mg} / \mathrm{kg}$ dose of the extract (Figure 11E).
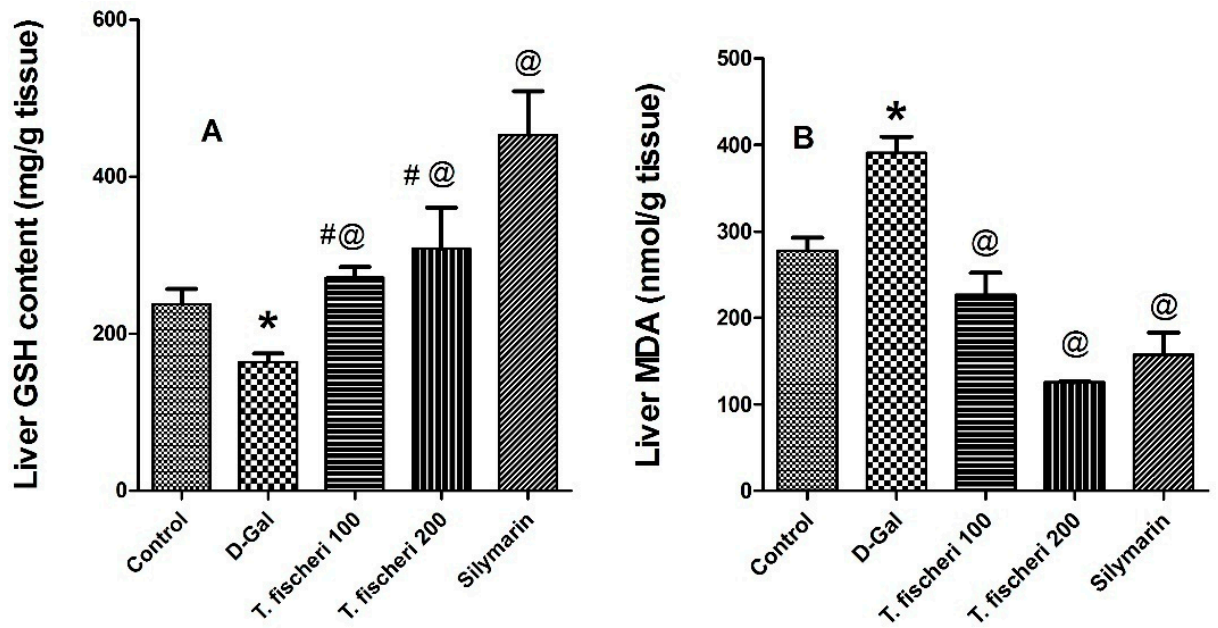

Figure 10. Influence of a single oral dose of D-galactosamine-induced liver injury $(800 \mathrm{mg} / \mathrm{kg})$ and oral administration of two doses (100 mg/ $\mathrm{kg}$ and $200 \mathrm{mg} / \mathrm{kg} \mathrm{b.w.)} \mathrm{of} \mathrm{T.} \mathrm{fischeri} \mathrm{extract} \mathrm{and} \mathrm{the}$ positive control silymarin (100 mg/kg) on (A) Reduced glutathione content (GSH, mg/g liver tissue); (B) Malondialdehyde content (MDA, nmol/g liver tissue). Results are expressed as mean \pm SEM. * Significant difference compared to normal control group; ${ }^{\circledR}$ Significant difference when compared to D-GalN treated group at $p<0.05$; " significant difference compared to silymarin treated group at $p<0.05, n=6$; by One Way ANOVA and Tukey post hoc test.

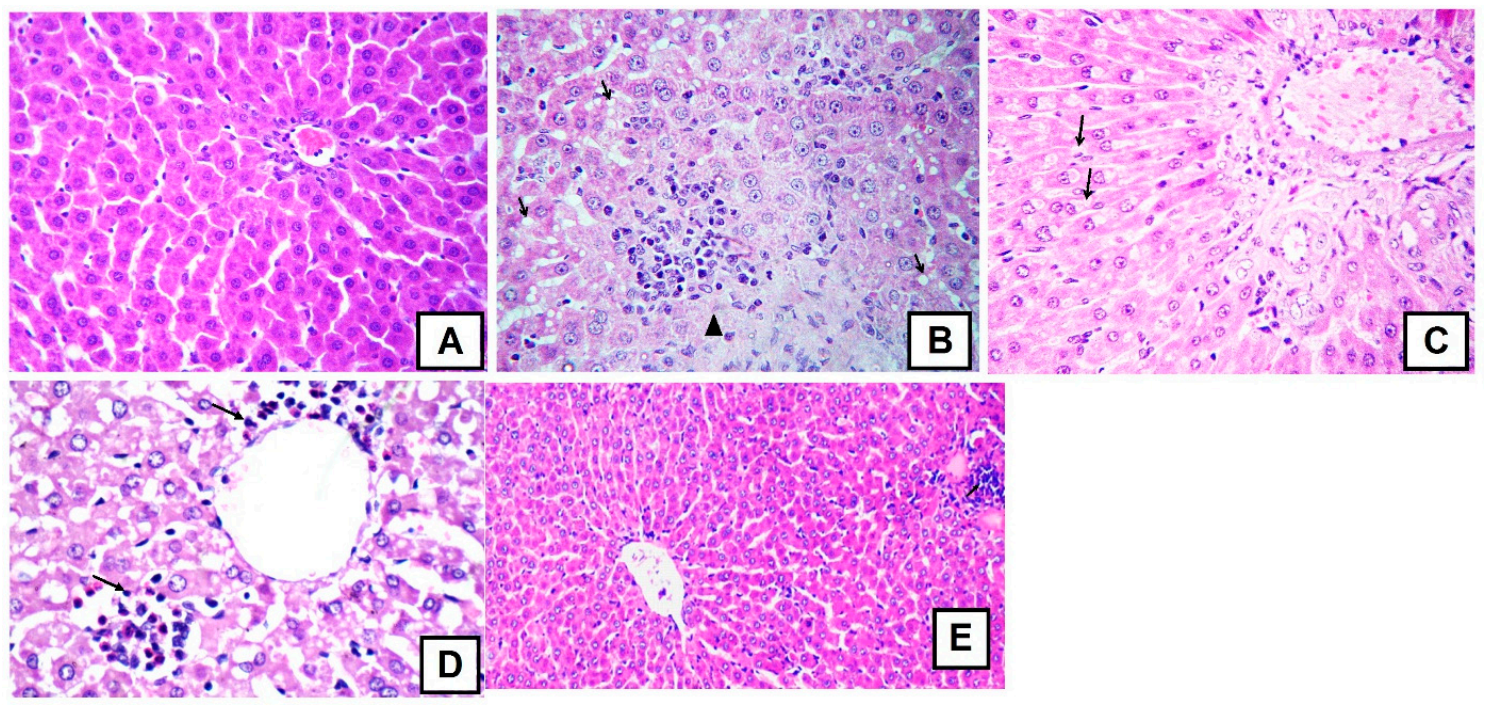

Figure 11. Representative photomicrographs of cross sections from six rat livers (staining with hematoxylin and eosin, 400×); (A) Liver of healthy rats with normal hepatocytes arranged in hepatic cords radiating from the central vein with normal portal area, central vein and normal ducts; (B) Liver of D-galactosamine treated rats showing focal hepatic necrosis infiltrated by mononuclear cells (arrow head) with microsteatosis of the adjacent hepatocytes (arrows); (C) Liver of extract $(100 \mathrm{mg} / \mathrm{kg})$ treated rats with minute fibrous strands in portal area and interlobular tissue with reversible degenerative changes mainly vacuolar degeneration in the hepatic cells (arrows); (D) Liver of extract $(200 \mathrm{mg} / \mathrm{kg}$ ) treated rats showing portal inflammation (arrows) but no steatosisornecrosis; and, (E) Liver of silymarin extract $(100 \mathrm{mg} / \mathrm{kg})$ treated rats showing partial improvement but some monocellular infiltration. 
To sum up, pronounced antioxidant and hepatoprotective effects were observed in different experimental models in vitro and in vivo in C. elegans and in rats. These results are in agreement with those reported for extracts containing cinchonains and phenylpropanoid-substituted cinchonains from Trichilia catigua and Parabarium huaitingii [14,15].

\section{Materials and Methods}

\subsection{Plant Material and Extraction}

The bark of Turraea fischeri was collected from Lupaga Site in Shinyanga, Tanzania. A sample is stored at IPMB, Heidelberg University under the accession number P7335. The dried and ground stembark (100 g) was defatted with n-hexane and then extracted with methanol (100\%) at ambient temperature $(3 \times 500 \mathrm{~mL})$. The filtrates were combined and evaporated under vacuum at $40{ }^{\circ} \mathrm{C}$ until dryness. The obtained residue was lyophilized yielding fine dried powder $(21 \mathrm{~g})$.

\subsection{HPLC-PDA-MS/MS}

The LC system was Thermo Finnigan (Thermo Electron Corporation, Waltham, MA, USA). The reversed-phase column (Zorbax Eclipse XDB-C18, rapid resolution, $4.6 \times 150 \mathrm{~mm}, 3.5 \mu \mathrm{m}$, Agilent, Santa Clara, CA, USA) was used. The mobile phase was water and acetonitrile (ACN) ( $0.1 \%$ formic acid each) and gradient was employed from $5 \%$ to $30 \%$ CAN in $60 \mathrm{~min}$ with flow rate $1 \mathrm{~mL} / \mathrm{min}$ with a 1:1 split before the ESI source. Autosampler surveyor ThermoQuest (Thermo Electron Corporation, Waltham, MA, USA) was used to inject the sample; the process was controlled by Xcalibur software (Xcalibur ${ }^{\mathrm{TM}}$ 2.0.7, Thermo Scientific, Waltham, MA, USA) [23]. LCQ-Duo ion trap mass spectrometer (ThermoQuest Corporation, Austin, TX, USA) with an ESI source (ThermoQuest) was used and operated in the negative mode as described before [22]. Full scan mode with a mass range of $50-2000 \mathrm{~m} / \mathrm{z}$ was employed to detect the ions.

\subsection{Antioxidant Activities}

In vitro antioxidant properties were determined according to DPPH radical scavenging activity and ferric reducing antioxidant power (FRAP) assays, as well as total phenolic content; they were done as reported before [24]. In vivo antioxidant potential was determined in Caenorhabditis elegans. The C. elegans strains [Wild type (N2), TJ375 [hsp-16.2::GFP (gpls1)] and TJ356] were obtained from the Caenorhabditis Genetic Center (CGC). The worms were maintained at $20{ }^{\circ} \mathrm{C}$ on nematode growth medium (NGM), and fed with living E. coli OP50. The cultures were synchronized by treating gravid adults with sodium hypochlorite. In M9 buffer, the eggs were hatched and obtained larvae were moved into S-media seeded with living E. coli OP50 (D.O600 = 1.0). For in vivo assays, in the survival rate, initially, the worms (N2) were incubated with three different concentrations $(25,50,100 \mu \mathrm{g})$ for $48 \mathrm{~h}$, and then juglone $(80 \mu \mathrm{M})$ was added for another $24 \mathrm{~h}$. The worms then were counted and the results were expressed as a mean of a percentage of live nematodes. Again, to determine the intracellular ROS concentration, the worms were incubated with three different concentrations of the extract for $48 \mathrm{~h}$. The worms were then incubated in M9 buffer contained $20 \mu \mathrm{M}$ H2DCF-DA at $20^{\circ} \mathrm{C}$ for $1 \mathrm{~h}$. Using fluorescence microscope (Keyence, BZ-9000, Osaka, Japan), the intracellular ROS concentration was measured using fluorescence intensity and then quantified by ImageJ 1.48 software (National Institutes of Health, Bethesda, MD, USA). Quantification of Phsp-16.2::GFP expression was studied in TJ375 strains while subcellular DAF-16::GFP localization was studied in the transgenic strain TJ356. All of the analyses were carried out according to our protocols described in more details $[11,12,25]$. 


\subsection{Hepatoprotective Experiments}

\subsubsection{Animals}

Thirty healthy male Wistar rats weighing 180-200 g were utilized in this study and were obtained from the animal house of the Faculty of Veterinary medicine, University of Zagazig, Zagazig, Egypt. The animals were kept in clean polypropylene cages under standard conditions (temperature: $25^{\circ} \mathrm{C}$; 12/12 h light dark cycle; relative humidity: about 50\%). A seven-day acclimatization period was allowed before the experiment and the rats were allowed free access to food and tap water. All of the treatments were in accordance with the Guide for the Care and Use of Laboratory Animals of National Academy of Sciences, USA (2011) [26]. Approval (number P5-6-2016) was granted by the Animal Ethics Committee of the Faculty of Pharmacy, Zagazig University prior to commencement of the study.

Rats were randomly assigned into five experimental groups. Each group contained equal numbers of male rats (i.e., $n=6$ ). Group (A) represents control group and was given a $1 \mathrm{~mL}$ single oral dose of vehicle, while group (B) received $800 \mathrm{mg} / \mathrm{kg}$ D-galactosamine (D-GaIN) dissolved in normal saline by intraperitoneal injection. Group (C) received a single oral dose of T. fischeri extract (100 mg/ $\mathrm{kg} \mathrm{b.w.).}$ Group (D) received single oral dose (200 $\mathrm{mg} / \mathrm{kg}$ b.w.) of T. fischeri extract. Group (E) represents a positive control, which received a single oral dose of silymarin (100 mg/kg b.w.), a known liver protecting natural product. One hour later, the animals of groups (C, D, and E) received $800 \mathrm{mg} / \mathrm{kg}$ D-galactosamine (D-GaIN) dissolved in normal saline by intraperitoneal injection. The extract and silymarin were suspended in gum acacia $(10 \mathrm{mg} / \mathrm{mL}$ saline $w / v)$.

\subsubsection{Blood and Tissue Sampling}

$24 \mathrm{~h}$ after D-GalN injection, rats were euthanized following anesthesia using diethylether (Fisher Scientific UK Ltd., Loughborough, UK) and $3 \mathrm{~mL}$ of venous blood were collected from each animal from the retro-orbital plexus in a plain tube. All of the blood samples were centrifuged $(3000 \times g$, $4^{\circ} \mathrm{C}$, and $15 \mathrm{~min}$ ) and the serum was separated and used to measure the levels of liver enzymes alanine aminotransferase (ALT), aspartate aminotransferase (AST), and gamma-glutamyltransferase (GGT), and total bilirubin.

For histopathology and oxidative stress measurement, a liver specimen of $1 \mathrm{~cm}$ length $\times 0.5 \mathrm{~cm}$ width $\times 0.5 \mu \mathrm{m}$ thicknesses was excised from each liver and washed off with cold saline. It was divided into two parts. One part was immediately flash frozen in liquid nitrogen and kept at $-80{ }^{\circ} \mathrm{C}$ for measurements of oxidative stress parameters, reduced glutathione and lipid peroxidation product, and malondialdehyde (GSH and MDA, respectively). The other part was processed embedded in paraffin and used for histopathological examination.

\subsubsection{Biochemical Determinations}

The serum levels of ALT, AST, GGT, and total bilirubin in the rats were measured using a colorimetric kit according to the instructions of the company (Diamond Co., Cairo, Egypt and Spectrum Co., Cairo, Egypt). One gram liver tissues were homogenized. Then lipid peroxidation product, malondialdehyde (MDA) and reduced glutathione (GSH) content were measured in tissue homogenate photometrically (spectrophotometer, Jenway®, Stone, UK) according to Ohkawa et al. [27] and Beutler et al. [28], respectively.

\subsubsection{Histology Studies}

Serial sections of 4-5 $\mu \mathrm{m}$ thickness were cut from each tissue block, mounted on slides, and kept at room temperature. Then they were dewaxed in xylene, hydrated using graded ethanol, and stained with hematoxylin and eosin (H\&E) (Abcam, Cambridge, MA, USA) to assess hepatic architecture and structural changes. All of the sections were examined with an EVOS XL core microscope (Thermo Fisher Scientific, Waltham, MA, USA) at $\times 100$ and $\times 400$ magnifications. The sections were photographed with a digital camera (Canon, Tokyo, Japan). 


\subsection{Statistical Analysis}

The values are presented as the means \pm SEM. Significant differences between all of the groups were assessed by one-way analysis of variance using the Tukey post hoc-test test and unpaired $t$ test. A value of $p<0.05$ was considered significant. A computer-based curve fitting program (GraphPad Prism 5, Inc., La Jolla, CA, USA) was used to perform statistical analysis.

\section{Conclusions}

In this study, we characterized the phytoconstituents of a methanol bark extract of T. fischeri. Altogether, 20 compounds were tentatively identified belonging to cinchonains and phenylpropanoid-substituted catechin. T. fischeri extract demonstrated substantial antioxidant and hepatoprotective properties. T. fischeri could be further studied to isolate its biologically-active phytoconstituents and to study their mechanism of action in more detail as this plant shows promising liver-protecting activities.

Acknowledgments: We acknowledge financial support by DeutscheForschungsgemeinschaft and Ruprecht-KarlsUniversität Heidelberg within the funding program Open Access Publishing.

Author Contributions: M.S. performed the extraction, chemical characterization of the extract, the antioxidant activities in vitro, analyzed the data, wrote the paper, conceived and designed the project. M.F.M. designed and performed the hepatoprotective experiments and wrote the paper. O.M.S. and R.A. participated in the chemical characterization of the extract. M.D. performed the antioxidant activities in vivo, A.M.E.-S. analyzed the data and revised the paper and M.W. revised the paper, conceived and designed the project.

Conflicts of Interest: The authors declare no conflict of interest.

\section{References}

1. Adly, A.A. Oxidative stress and disease: An updated review. Res. J. Immunol. 2010, 3, 129-145.

2. Van Wyk, B.-E.; Wink, M. Phytomedicines, Herbal Drugs and Poisons; University of Chicago Press: Chicago, IL, USA, 2015.

3. Van Wyk, B.-E.; Wink, M. Medicinal Plants of the World, 2nd ed.; CABI: Wallingford, UK, 2017.

4. Mabberley, D.J. Mabberley's Plant-Book: A Portable Dictionary of Plants, Their Classifications and Uses, 3rd ed.; Cambridge University Press: Cambridge, UK, 2008.

5. Yuan, C.-M.; Tang, G.-H.; Zhang, Y.; Wang, X.-Y.; Cao, M.-M.; Guo, F.; Li, Y.; Di, Y.-T.; Li, S.-L.; Hua, H.-M. Bioactive limonoid and triterpenoid constituents of Turraea pubescens. J. Nat. Prod. 2013, 76, 1166-1174. [CrossRef] [PubMed]

6. Mokoka, T.A.; Xolani, P.K.; Zimmermann, S.; Hata, Y.; Adams, M.; Kaiser, M.; Moodley, N.; Maharaj, V.; Koorbanally, N.A.; Hamburger, M. Antiprotozoal screening of 60 South African plants, and the identification of the antitrypanosomal germacranolides schkuhrin I and II. Planta Med. 2013, 79, 1380-1384. [CrossRef] [PubMed]

7. Ogbole, O.O.; Saka, Y.A.; Fasinu, P.S.; Fadare, A.A.; Ajaiyeoba, E.O. Antimalarial and cytotoxic properties of Chukrasia tabularis A. Juss and Turraea vogelii Hook F. Ex. Benth. Parasitol. Res. 2016, 115, 1667-1674. [CrossRef] [PubMed]

8. Nibret, E.; Ashour, M.L.; Rubanza, C.D.; Wink, M. Screening of some Tanzanian medicinal plants for their trypanocidal and cytotoxic activities. Phytother. Res. 2010, 24, 945-947. [CrossRef] [PubMed]

9. Neuwinger, H.D. African Ethnobotany: Poisons and Drugs: Chemistry, Pharmacology, Toxicology; CRC Press: Weinheim, Germany, 1996.

10. Augustino, S.; Hall, J.B.; Makonda, F.B.; Ishengoma, R.C. Medicinal Resources of the Miombo woodlands of Urumwa, Tanzania: Plants and its uses. J. Med. Plants Res. 2011, 5, 6352-6372.

11. Su, S.; Wink, M. Natural lignans from Arctium lappa as antiaging agents in Caenorhabditis elegans. Phytochemistry 2015, 117, 340-350. [CrossRef] [PubMed]

12. Wang, E.; Wink, M. Chlorophyll enhances oxidative stress tolerance in Caenorhabditis elegans and extends its lifespan. Peer] 2016, 4, e1879. [CrossRef] [PubMed]

13. Gu, W.Y.; Li, N.; Leung, E.L.H.; Zhou, H.; Yao, X.J.; Liu, L.; Wu, J.L. Rapid identification of new minor chemical constituents from Smilacis glabrae rhizoma by combined use of UHPLC-Q-TOF-MS, preparative HPLC and UHPLC-SPE-NMR-MS techniques. Phytochem. Anal. 2015, 26, 428-435. [CrossRef] [PubMed] 
14. Resende, F.O.; Rodrigues-Filho, E.; Luftmann, H.; Petereit, F.; Mello, J.C. Phenylpropanoid substituted flavan-3-ols from Trichilia catigua and their in vitro antioxidative activity. J. Braz. Chem. Soc. 2011, 22, 2087-2093. [CrossRef]

15. Tang, J.S.; Gao, H.; Wang, C.X.; Dai, Y.; Bao, L.; Ye, W.C.; Yao, X.S. Antioxidative phenylpropanoid-substituted epicatechin glycosides from Parabarium huaitingii. Planta Med. 2009, 75, 1586-1590. [CrossRef] [PubMed]

16. Kokke, B.P.; Leroux, M.R.; Candido, E.P.M.; Boelens, W.C.; de Jong, W.W. Caenorhabditis elegans small heat-shock proteins Hsp12.2 and Hsp12.3 form tetramers and have no chaperone-like activity. FEBS Lett. 1998, 433, 228-232. [CrossRef]

17. Grünz, G.; Haas, K.; Soukup, S.; Klingenspor, M.; Kulling, S.E.; Daniel, H.; Spanier, B. Structural features and bioavailability of four flavonoids and their implications for lifespan-extending and antioxidant actions in C. elegans. Mech. Ageing Dev. 2012, 133, 1-10.

18. Abbas, S.; Wink, M. Green tea extract induces the resistance of Caenorhabditis elegans against oxidative stress. Antioxidants 2014, 3, 129-143. [CrossRef] [PubMed]

19. Sobeh, M.; Mahmoud, M.; Hasan, R.; Cheng, H.; El-Shazly, A.; Wink, M. Senna singueana: Antioxidant, hepatoprotective, antiapoptotic properties and phytochemical profiling of a methanol bark extract. Molecules 2017, 22, 1502. [CrossRef] [PubMed]

20. Abbas, S.; Wink, M. Epigallocatechin gallate from green tea (Camellia sinensis) increases lifespan and stress resistance in Caenorhabditis elegans. Planta Med. 2009, 75, 216-221. [CrossRef] [PubMed]

21. Abbas, S.; Wink, M. Epigallocatechin gallate inhibits beta amyloid oligomerization in Caenorhabditis elegans and affects the daf-2/insulin-like signaling pathway. Phytomedicine 2010, 17, 902-909. [CrossRef] [PubMed]

22. Sobeh, M.; Mahmoud, M.F.; Abdelfattah, M.A.; El-Beshbishy, H.A.; El-Shazly, A.M.; Wink, M. Albizia harveyi: Phytochemical profiling, antioxidant, antidiabetic and hepatoprotective activities of the bark extract. Med. Chem. Res. 2017, 26, 3091-3105. [CrossRef]

23. Sobeh, M.; Mahmoud, M.F.; Abdelfattah, M.A.O.; El-Beshbishy, H.A.; El-Shazly, A.M.; Wink, M. Hepatoprotective and hypoglycemic effects of a tannin rich extract from Ximenia americana var. caffra root. Phytomedicine 2017, 33, 36-42. [CrossRef] [PubMed]

24. Ghareeb, M.A.; Mohamed, T.; Saad, A.M.; Refahy, L.A.-G.; Sobeh, M.; Wink, M. HPLC-DAD-ESI-MS/MS analysis of fruits from Firmiana simplex (L.) and evaluation of their antioxidant and antigenotoxic properties. J. Pharm. Pharmacol. 2017. [CrossRef] [PubMed]

25. Sobeh, M.; Mahmoud, M.F.; Abdelfattah, M.A.O.; Cheng, H.; El-Shazly, A.M.; Wink, M. A proanthocyanidinrich extract from Cassia abbreviata exhibits antioxidant and hepatoprotective activities in vivo. J. Ethnopharmacol. 2018, 213, 38-47. [CrossRef] [PubMed]

26. Council, N.R. Guide for the Care and Use of Laboratory Animals; National Academies Press: Washington, DC, USA, 2010.

27. Ohkawa, H.; Ohishi, N.; Yagi, K. Assay for lipid peroxides in animal tissues by thiobarbituric acid reaction. Anal. Biochem. 1979, 95, 351-358. [CrossRef]

28. Beutler, E.; Duron, O.; Kelly, B.M. Improved method for the determination of blood glutathione. J. Lab. Clin. Med. 1963, 61, 882-888. [PubMed]

Sample Availability: Samples of plant materials are available from the authors. 